\title{
Effects on antibiotic dispensing rates of interventions to promote delayed prescribing for respiratory tract infections in primary care
}

\begin{abstract}
\section{Background}

Delayed antibiotic prescribing is an effective method of reducing the consumption of antibiotics for respiratory tract infections (RTIs). However, interventions to promote its use remain unexplored.

\section{Aim}

To measure the effects of a GP educational intervention and a computer delayed-prescribing pop-up reminder on antibiotic-dispensing rates. The study also aimed to identify factors influencing GPs' decisions to issue delayed prescriptions and patients' decisions to fill their prescriptions.

\section{Design and setting}

Controlled trial nested within a clusterrandomised controlled trial in urban and rural practices in 11 counties in southern Norway.
\end{abstract}

\section{Method}

Educational intervention and control groups were randomly populated from 81 continuing medical education groups. Within the intervention arm, 107 of the 156 participating GPs were assigned, based on the electronic patient-record system they used, to having a pop-up reminder installed on their computers. Data on prescribed and dispensed antibiotics from 1 year before, and 1 year during. the intervention were collected and linked.

\section{Results}

Valid data were obtained from 328 GPs (75\%). At baseline, $92.1 \%$ of prescriptions were filled at pharmacies. The effect of the educational intervention was a $1 \%$ reduction in approximated risk (risk ratio [RR] 0.99, 95\% confidence interval. $[\mathrm{Cl}=0.96$ to 1.01 ) of antibiotics being dispensed, while the combined effect of the educational and pop-up reminder intervention was a $4 \%$ reduction in approximated risk (RR 0.96, 95\% $\mathrm{Cl}=0.94$ to 0.98 ). In the pop-up intervention group, $11.0 \%$ of the prescriptions were issued as delayed prescriptions and $59.2 \%$ of these were filled. Upper RTI, sinusitis, and otitis gave highest odds for delayed prescribing and lowest odds for dispensing.

\section{Conclusion}

Promoting delayed prescribing among GPs results in a small decrease in antibiotic dispensing. The savings potential is greatest for upper RTI, sinusitis, and otitis.

\section{Keywords}

antibacterial agents; general practice; physicians practice patterns; reminder systems; respiratory tract infections.

\section{INTRODUCTION}

The majority of antibiotics are prescribed in primary care, most often for respiratory tract infections (RTIs)., ${ }^{1,2}$ Antibiotics, however, have only a modest effect in RTIs. ${ }^{3}$ Widespread use of antibiotics promotes the development of resistant bacteria and unnecessary use should be avoided. Numerous educational interventions have been conducted to encourage GPs to be more prudent when prescribing antibiotics for RTIs. Multifaceted interventions ${ }^{4}$ and strategies that use active clinician education and target the management of all RTIs seem to be the most effective.

The efficacy of different prescribing strategies in reducing the unnecessary use of antibiotics for RTIs has been tested in randomised controlled trials. Delayed prescribing, or the practice of prescribing antibiotics for patients but advising them not to take the medication unless the condition deteriorates or does not improve within a specified period, has proven effective in this regard, with acceptable patient satisfaction and symptom control.6.7 The practice of delayed prescribing has been advocated in several editorials ${ }^{8-10}$ and guidelines, 11,12 but it is used infrequently. ${ }^{13} \mathrm{~A}$ Cochrane review concludes that the strategy presents no advantages over not prescribing. ${ }^{14}$ Concern has also been raised that encouraging delayed prescribing may induce GPs to issue prescriptions more liberally, ${ }^{15}$ and that it is unlikely that delayed prescribing reduces antibiotic use in routine care..$^{16}$ There is, therefore, a need for more

S Høye, MD, PhD, researcher; $\mathbf{S}$ Gjelstad, MD, researcher; $\mathbf{M}$ Lindbæk, MD, PhD, professor of general practice, Antibiotic Center for Primary Care, University of Oslo, Oslo, Norway.

\section{Address for correspondence}

Sigurd Høye, Antibiotic Center for Primary Care, Department of General Practice, Institute of Health and Society, University of Oslo, PO Box 1130 Blindern, N-0318 Oslo, Norway. research on the effectiveness and feasibility of delayed prescribing.

The researchers of this study were not aware of reported studies on strategies designed to increase GPs' use of delayed prescribing. With one exception, ${ }^{17}$ all educational intervention studies on prudent antibiotic prescribing for RTIs have measured the doctor's prescribing behaviour, rather than the proportion of dispensed, or consumed, antibiotics. There could be a considerable difference between the amounts of antibiotics that are prescribed and dispensed. ${ }^{18}$

Studies evaluating the delayedprescribing strategy have been based mainly on patients' self-reported antibiotic use in trial and survey settings. Selfreporting as a data-collection method and the knowledge of being in a trial may introduce bias; by contrast, measuring medication dispensing at pharmacies may give more-valid results on the effect of delayed prescribing in routine care.

The main aim of this study was to investigate whether a tailored, combined educational intervention for GPs, which included a recommendation of delayed prescribing and a computerised popup reminder about delayed prescribing, would alter the proportion of antibiotic prescriptions dispensed at pharmacies. The study also aimed to investigate and identify factors affecting GPs' decisions to issue delayed prescriptions and patients' decisions to fill their antibiotic prescriptions.

E-mail: sigurd.hoyedamedisin.uio.no

Submitted: 5 April 2013; Editor's response:

23 April 2013; final acceptance: 20 June 2013 CBritish Journal of General Practice This is the full-length article (published online 28 Oct 2013) of an abridged version published in print. Cite this article as: Br J Gen Pract 2013; DOI: 10.3399/bjgp13X674468 


\section{How this fits in}

Trials have shown that delayed antibiotic prescribing is effective for reducing antibiotic consumption for respiratory tract infections (RTIs), and the strategy is recommended in several guidelines. Nevertheless, the strategy is used infrequently in general practice and a concern is that encouraging delayed prescribing may lead GPs to prescribe antibiotics more liberally. Interventions to promote delayed prescribing have not been conducted. This study shows that an educational intervention recommending delayed prescribing, used in combination with a pop-up reminder that appears on a computer screen to encourage delayed prescribing, reduces the proportion of prescribed antibiotics that are dispensed at pharmacies. GPs who are encouraged to use delayed prescribing do not prescribe antibiotics more frequently than other GPs. This strategy's potential for reducing antibiotic consumption is largest for acute otitis, acute sinusitis, and upper RTIs in younger patients $(<45$ years).

\section{METHOD}

This study was conducted as part of the Prescription Peer Academic Detailing (Rx-PAD) study, a cluster randomised educational intervention for GPs aimed at improving the quality of prescribing within two clinical areas: antibiotics for RTIs and potentially harmful medication for people aged $>70$ years. The participating continuing medical education (CME) groups were randomised to one of these arms, with each arm serving as a control for the other. The tailored intervention has been described in detail elsewhere. ${ }^{19}$

The elements of the intervention were two educational outreach visits at the participants' CME groups and a 1-day regional seminar. The outreach visits in the RTIs arm comprised:

- presentations and discussion of the national guidelines on appropriate antibiotic use for RTIs ${ }^{20}$ and evidencebased prescribing;

- the collection of individual prescription data; and

- an audit based on individual feedback reports.

The main outcome measures were prescription rates and the proportion of non-penicillin $V$ compared with the control group. As for the delayed-prescribing part of the Rx-PAD study presented in this article, two interventions were conducted:

- Educational intervention: delayed prescribing, described as giving the patient a prescription and advising to delay for a certain amount of time before deciding whether to fill it, was presented and recommended at the Rx-PAD outreach visits and the 1-day seminar.

- Pop-up intervention: one group of the RTI-arm GPs, chosen based on the electronic patient-record (EPR) system they used, had a compatible pop-up software application installed on their computers. Printing a prescription for antibiotics from the computer would trigger a screen pop-up requesting confirmation that the prescription was a delayed prescription

Data on all consultations for RTIS and all prescribed antibiotics from the participating GPs 1 year prior to the intervention (1 December 2004 until 30 November 2005), and 1 year during/ after the intervention (1 March 2006 until 28 February 2007), were extracted from the GPs' EPR systems. These data were merged with data from the Norwegian Prescription Database (NorPD), a national registry of all prescriptions dispensed at Norwegian pharmacies. This allowed the researchers to record whether a prescription was actually dispensed at a pharmacy. Prescriptions were matched in the two datasets according to the Anatomical Therapeutic Chemical (ATC) Classification System, the GP's health personnel number, the patient's birth number, and whether the dispensing date was within 21 days of the prescription date.

\section{Statistical analysis}

A multilevel logistic regression analysis was performed on the baseline data, with the dependent variable being dispensing/ not dispensing of the prescribed antibiotics at a pharmacy. The independent variables were GP and patient characteristics. A similar analysis was performed on the intervention data, with interventiongroup membership being an independent variable. A multilevel logistic regression analysis was performed on the intervention data, with the dependent variable being the issuing of a delayed prescription by the GP. To adjust for clustering, random intercepts at the two levels of GP and CME group were included. The random effects included were statistically significant.

Adjusted odds ratios (ORs) cannot 


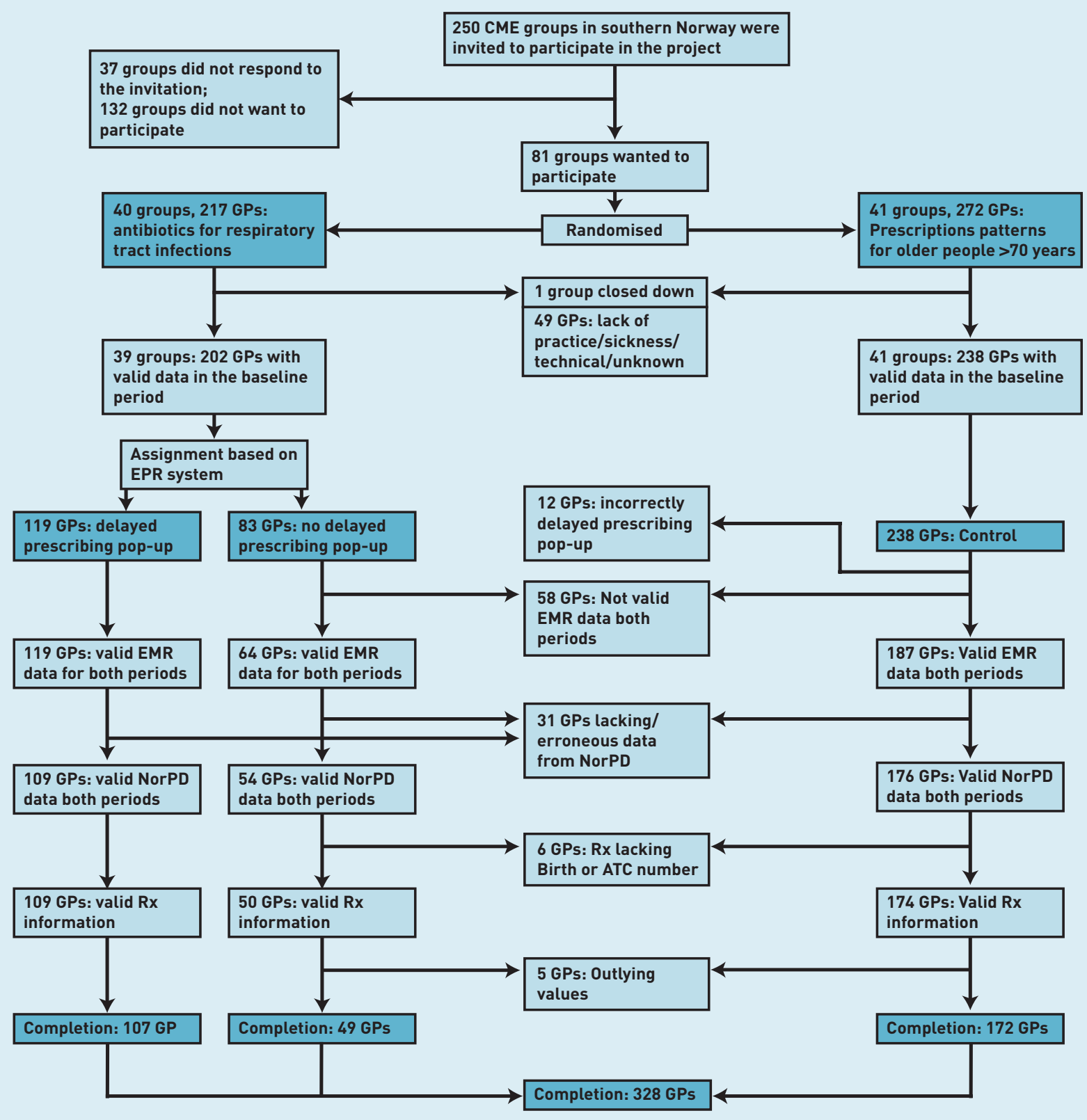

Figure 1. Flowchart of included GPs in the study.

approximate the risk ratios (RRs) when the incidence of the outcome of interest is common (>10\%). ${ }^{21}$ As the outcome of this study - prescriptions being dispensed - is very common, the RRs were approximated from the ORs using a standard correction method. ${ }^{21}$

$\mathrm{A} \chi^{2}$ testwas used to compare prescription rates between the pop-up intervention and the educational intervention groups. A significance level of $5 \%$ was applied. The descriptive analyses were performed using PASW Statistics 18 and the multilevel regression analyses were performed using Stata 11.2.

\section{Materials}

All 250 CME groups in 11 counties in the southern part of Norway were invited to participate in the Rx-PAD study, 81 of which accepted. Of these, 41 groups were randomised to the control arm and 40 groups to the intervention arm. Figure 1 shows drop-outs from the study. One CME group was closed down before intervention took place.

Prescription data from the baseline period were provided by 440 GPs, 382 of whom also provided data from the intervention period. As a result of combinations of late delivery of data, missing patient birth 
Table 1. Characteristics of participating GPs $(n=328)$

\begin{tabular}{|c|c|c|c|}
\hline & \multirow{2}{*}{$\begin{array}{l}\text { Control for } \\
\text { educational } \\
\text { intervention } \\
\quad n=172\end{array}$} & \multicolumn{2}{|c|}{ Educational intervention, $n(\%)$} \\
\hline & & $\begin{array}{l}\text { Control for pop-up } \\
\text { intervention } \\
\qquad \begin{array}{l}n=49\end{array}\end{array}$ & $\begin{array}{c}\text { Pop-up } \\
\text { intervention } \\
n=107\end{array}$ \\
\hline \multicolumn{4}{|l|}{ Sex, $n[\%]$} \\
\hline Female & 58 (33.7) & $18(36.7)$ & $36(33.6)$ \\
\hline Male & 114 (66.3) & 31 (63.3) & $71(66.4)$ \\
\hline \multicolumn{4}{|l|}{ Practice location, $n(\%)$} \\
\hline Urban & 92 (53.5) & 32 (65.3) & 56 (52.3) \\
\hline Rural & $80(46.5)$ & 17 (34.7) & $51(47.7)$ \\
\hline \multicolumn{4}{|l|}{ Practice type, $n(\%)$} \\
\hline Group & $159(92.4)$ & $46(93.9)$ & $97(90.7)$ \\
\hline Solo & $13(7.6)$ & $3(6.1)$ & $10(9.3)$ \\
\hline \multicolumn{4}{|l|}{ GP specialist, $n[\%]$} \\
\hline Yes & 159 (92.4) & $40(81.6)$ & $90(84.1)^{a}$ \\
\hline No & $13(7.6)$ & 9 (18.4) & $17(15.9)$ \\
\hline Mean age, years (SD) & $50.1(7.6)$ & $47.6(9.0)$ & $48.5(7.6)$ \\
\hline Years since authorisation, mean (SD) & $20.6(8.0)$ & $16.8(9.3)$ & $18.3(8.4) \mathrm{a}$ \\
\hline Listed patients, mean (SD) ${ }^{\mathrm{b}}$ & 1329 (329) & 1489 (358) & 1339 (383)a \\
\hline Patient encounters per year, mean (SD) & 3053 (1250) & $2994(906)$ & $3191(1055)$ \\
\hline
\end{tabular}

numbers, and/or medication ATC codes, or incorrectly installed software, 49 GPs were excluded from the study. Five GPs showed a highly deviant increase in the dispensing rate from baseline to intervention period, probably because of shortcomings in data registration during the period after NorPD was established in January 2004; it was decided that these five outlying GPs should be excluded.

Analysis was conducted on data from the remaining $328 \mathrm{GPs}$ and 72512 prescriptions from 237588 consultations. Table 1 details the characteristics of the participating GPs.

\section{RESULTS}

\section{Factors associated with antibiotic dispensing: baseline data}

At baseline, $92.1 \%$ of the prescribed antibiotics were dispensed at pharmacies (Table 2). The multilevel logistic regression analysis revealed that the GPs' own listed patients had higher odds of filling prescriptions for antibiotics than patients on other GPs' lists. Patients of rural practices also filled antibiotics more frequently than those of urban practices. The sex, practice type, age, specialist status, and workload of GPs did not significantly affect patients rates of filling prescriptions.

Patients with upper RTIs and symptoms, acute sinusitis, or acute otitis media had approximately half the odds of filling a prescription for antibiotics compared with patients with pneumonia or acute tonsillitis. Moreover, the oldest age groups had twice the odds of filling a prescription compared with the youngest groups (Table 2).

\section{Effect of interventions}

There were no significant differences in dispensing rates between the intervention and control groups at baseline $(P=0.81)$. During the intervention, the pop-up intervention group's dispensing rate decreased to $90.2 \%$ and the educational intervention group's dispensing rate decreased to 91.8\%; the control group's dispensing rate increased to $92.4 \%$ (Table 3). In the pop-up intervention group, only $59.2 \%$ of the delayed prescriptions were dispensed, whereas $94.3 \%$ of the immediate prescriptions were filled (Table 3). Multilevel logistic regression analysis revealed that the approximated risk of a prescription being dispensed if it was issued by a GP in the pop-up intervention group was 0.96 $195 \%$ confidence interval $[\mathrm{Cl}]=0.94$ to 0.98 , reference: control group) (Table 4).

The effect of the educational intervention on the antibiotic prescription rate, as opposed to the dispensing rate, will be reported in detail in a separate article. The pop-up intervention had no effect on prescription rate; both GPs in the popup intervention group and the educational intervention group prescribed antibiotics in $29.3 \%$ of the RTI consultations during the intervention $(P=0.90)$. There was no significant difference in prescription rate between these two groups at baseline $(P=$ 0.66) (data not shown).

\section{Factors associated with delayed prescribing}

From 10860 pop-up responses, 1194 $(11.0 \%)$ were delayed prescriptions, accounting for $3.0 \%$ of all patients consulting a GP in the pop-up intervention group for an RTI. Table 5 sets out the characteristics of the delayed prescribing consultations and the odds of issuing a delayed prescription. Female GPs practised delayed prescribing almost twice as often as their male colleagues. Nevertheless, in the multilevel logistic regression analysis, none of the GP factors was significantly associated with issuing delayed prescriptions.

All of the patient factors, including age, sex, and diagnosis, had significant impacts on the odds of receiving a delayed prescription. Patients aged $\leq 18$ years were two to three times as likely to be exposed to the strategy compared with patients aged $\geq 65$ years. Patients diagnosed with upper 


\section{Table 2. Factors independently associated with dispensing prescribed antibiotics (multilevela logistic regression analysis at baseline)}

\begin{tabular}{|c|c|c|c|}
\hline $\begin{array}{r}\text { Disp } \\
\text { l\% of pr }\end{array}$ & $\begin{array}{l}\text { ensed prescriptions } \\
\text { escribed prescriptions) }\end{array}$ & OR $(95 \% \mathrm{Cl})$ & $P$-value \\
\hline Total & $32347(92.1)$ & & \\
\hline \multicolumn{4}{|l|}{ GP factors $^{b}$} \\
\hline \multicolumn{4}{|l|}{ Sex } \\
\hline Male & $22587(92.3)$ & 1 (Reference) & \\
\hline Female & $9760(91.7)$ & $1.00(0.85$ to 1.18$)$ & 0.990 \\
\hline \multicolumn{4}{|l|}{ Practice location } \\
\hline Urban & 18787 [91.5) & 1 (Reference) & \\
\hline Rural & $13560(92.9)$ & $1,21(1.03$ to 1.41$)$ & 0.020 \\
\hline \multicolumn{4}{|l|}{ Practice type } \\
\hline Group & 29747 (92.0) & 1 (Reference) & \\
\hline Solo & $2600(93.1)$ & $0.96(0.74$ to 1.25$)$ & 0.770 \\
\hline \multicolumn{4}{|l|}{ GP specialist } \\
\hline Yes & $29431(92.2)$ & 1 (Reference) & \\
\hline No & $2916(90.6)$ & 0.93 (0.73 to 1.20 ) & 0.590 \\
\hline \multicolumn{4}{|l|}{ Listed patients } \\
\hline On own list & $23910(92.5)$ & 1 (Reference) & \\
\hline On other GP's list & $6556(91.5)$ & $0.85(0.77$ to 0.94$)$ & 0.002 \\
\hline 'Unlisted' & $1881(89.4)$ & 0.74 (0.63 to 0.87 ) & $<0.001$ \\
\hline \multicolumn{4}{|l|}{$\mathrm{AB}^{\mathrm{C}}$ prescribing rate, quintiles $(\%)$} \\
\hline $11.7-23.1 \%$ (66 GPs) & 3110 (92.5) & 1 (Reference) & \\
\hline $23.3-28.5 \%$ (69 GPs) & $5176(90.0)$ & $0.75(0.59$ to 0.96$)$ & 0.020 \\
\hline $28.6-33.6 \%$ (64 GPs) & $5453(91.9)$ & 0.85 (0.66 to 1.08 ) & 0.190 \\
\hline $33.7-41.2 \%$ (65 GPs) & $7477(93.4)$ & 1.01 (0.79 to 1.30$)$ & 0.930 \\
\hline $41.5-71.3 \%$ (64 GPs) & $11131(92.2)$ & 0.88 (0.69 to 1.13 ) & 0.320 \\
\hline \multicolumn{4}{|l|}{ Patient factors } \\
\hline \multicolumn{4}{|l|}{ Type of ARTI } \\
\hline URTIs and RT symptoms & 7892 (90.2) & 1 (Reference) & \\
\hline Acute tonsillitis & 4428 (93.8) & 1.75 (1.51 to 2.03$)$ & $<0.001$ \\
\hline Acute sinusitis & 5911 (91.3) & $1.04(0.92$ to 1.17$)$ & 0.560 \\
\hline Acute bronchitis & 5391 (93.8) & $1.45(1.26$ to 1.66$)$ & $<0.001$ \\
\hline Pneumonia & 3604 (95.8) & 2.03 (1.69 to 2.43 ) & $<0.001$ \\
\hline Acute otitis media and ear pain & $3179(88.0)$ & $0.85(0.74$ to 0.98$)$ & 0.028 \\
\hline Other RTIs & 1942 (93.9) & $1.35(1.10$ to 1.67$)$ & 0.004 \\
\hline \multicolumn{4}{|l|}{ Sex } \\
\hline Male & 13304 (91.9) & 1 (Reference) & \\
\hline Female & $19043(92.2)$ & $1.05(0.96-1.14)$ & 0.270 \\
\hline \multicolumn{4}{|l|}{ Age, years } \\
\hline$\leq 6$ & $4166(89.1)$ & 1 (Reference) & \\
\hline $6-12$ & $2242(91.6)$ & $1.18(0.99-1.40)$ & 0.070 \\
\hline 13-18 & 1778 (92.2) & $1.19(0.97-1.45)$ & 0.100 \\
\hline $19-44$ & $12134(90.8)$ & $1.09(0.96-1.24)$ & 0.200 \\
\hline 45-64 & $8017(93.7)$ & $1.56(1.34-1.81)$ & $<0.001$ \\
\hline 65-79 & $3032(96.6)$ & $2.74(2.18-3.45)$ & $<0.001$ \\
\hline$\geq 80$ & 978 (95.3) & $1.73(1.26-2.38)$ & 0.001 \\
\hline
\end{tabular}

${ }^{2}$ Adjusted for clustering by random intercepts at GP and continuing medical education group level. ${ }^{b} T h e ~ G P$ factors of age and patient encounters/year were non-significant and have been omitted from the table. ${ }^{C} A B$ $=$ antibiotic prescribing. $A R T I=$ acute respiratory tract infection. $O R=$ odds ratio. $R T=$ respiratory tract. $R T I=$ respiratory tract infection. URTI $=$ upper respiratory tract infection .

\section{DISCUSSION}

\section{Summary}

At baseline, $92.1 \%$ of prescriptions for antibiotics were dispensed at pharmacies. An educational intervention on prudent antibiotic prescribing and a recommendation of delayed prescribing, combined with a pop-up reminder on delayed prescribing, decreased the approximated risk of antibiotics being dispensed (RR 0.96), without any increase in antibiotic prescribing. An educational intervention and recommendation of delayed prescribing alone produced a small and not statistically significant reduction in the risk of antibiotics being dispensed (RR 0.99).

Having pneumonia or acute tonsillitis, and being of older age, increased the odds of the prescription being filled at a pharmacy. Patients with acute sinusitis, otitis media, or upper RTI and symptoms, and patients of younger age had the highest odds of receiving a delayed prescription.

\section{Strengths and limitations}

To date, this is the largest study examining the outcomes of delayed prescriptions. To the authors' knowledge, it is also the first educational intervention study on using antibiotics to treat RTls that includes a recommendation for delayed prescribing, and that uses the antibiotic-dispensing rate to measure the effect. Despite some limitations, the study offers important and useful information on the potential of delayed prescribing for reducing antibiotic use to treat RTIs.

Only 81 of the 250 (32.4\%) CME groups invited agreed to participate in this study. This low participation rate invites the possibility of selection bias. The distribution of different classes of antibiotics prescribed by the GPs agreeing to take part in the study was similar to that of all other specialist GPs in Norway. ${ }^{22}$ Prescription rates are associated highly with the distribution of prescribed narrow-spectrum and broadspectrum antibiotics, ${ }^{22}$ hence, the antibioticprescribing practices of the participating GPs were representative of Norwegian GPs as a whole.

A substantial proportion of GPs was excluded from the study because of missing data or delayed data delivery. There were significantly more female GPs (34\% versus $22 \%$ ) and specialist GPs $189 \%$ versus $80 \%$ ) among the included GPs than among the excluded GPs. On all other GP characteristics, including antibiotic prescription rate, there were no significant differences between the GPs included and those who were excluded. 


\section{Table 3. Number of dispensed prescriptions (\% of prescribed prescriptions) during intervention period}

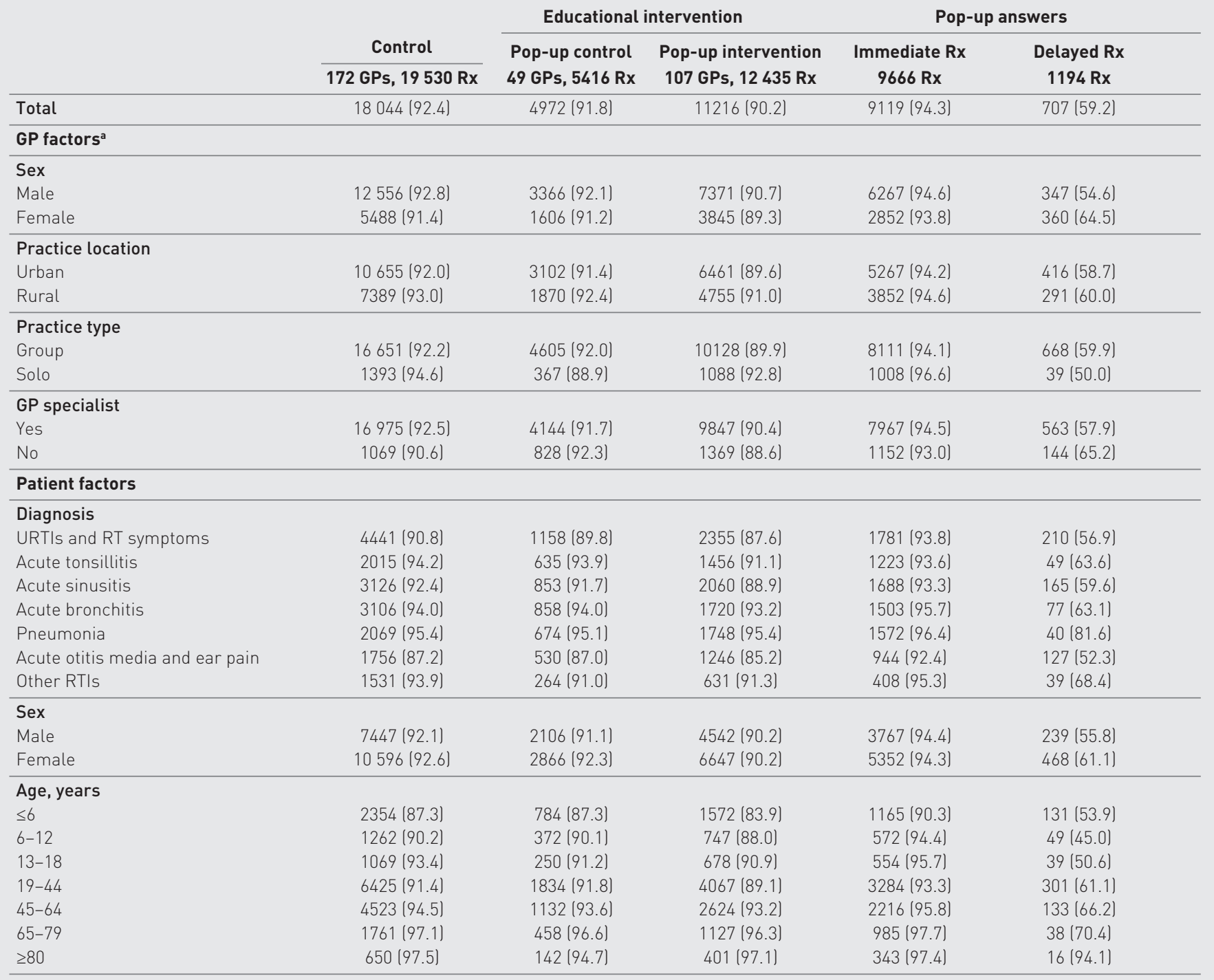

The GP factors of age, patient encounters/year, listed patients, and antibiotic prescribing rates have been omitted from the table. OR=odds ratio. $R T=$ respiratory tract. $R T I$ = respiratory tract infection. URTI = upper respiratory tract infection.

Table 4. Crude and adjusted ${ }^{a}$ odds ratios and approximated risk ratios ${ }^{\text {b }}$ for dispensing prescribed antibiotics, according to prescribers' intervention group (multilevel' logistic regression analysis, intervention period]

\begin{tabular}{|c|c|c|c|c|}
\hline Intervention & $\begin{array}{l}\text { Crude OR } \\
(95 \% \mathrm{CI})\end{array}$ & $\begin{array}{l}\text { Adjusted OR } \\
\text { (95\% CI] }\end{array}$ & $P$-value & $\operatorname{RR}(95 \% \mathrm{CI})$ \\
\hline Control & 1 (Reference) & 1 (Reference) & & \\
\hline Educational intervention alone & $\begin{array}{c}0.84 \\
(0.66 \text { to } 1.07)\end{array}$ & $\begin{array}{c}0.87 \\
(0.69 \text { to } 1.09)\end{array}$ & 0.230 & $\begin{array}{c}0.99 \\
(0.96 \text { to } 1.01)\end{array}$ \\
\hline $\begin{array}{l}\text { Pop-up and educational } \\
\text { intervention }\end{array}$ & $\begin{array}{c}0.75 \\
(0.61 \text { to } 0.91)\end{array}$ & $\begin{array}{c}0.72 \\
(0.60 \text { to } 0.86)\end{array}$ & $<0.001$ & $\begin{array}{c}0.96 \\
(0.94 \text { to } 0.98)\end{array}$ \\
\hline \multicolumn{5}{|c|}{$\begin{array}{l}{ }^{a} \text { Adjusted for GP sex, practice location, practice type, specialist status, age, patient encounters/year, antibiotics } \\
\text { prescribing rate, patient's type of RTI, sex, age, and whether the patient was on GP's list. }{ }^{b} \text { Approximated from the } \\
\text { adjusted odds ratios using a standard correction method. }{ }^{21} \text { 'Adjusted for clustering by random intercepts at GP and } \\
C M E \text { group level. OR = odds ratio. RT = respiratory tract. } R T I=\text { respiratory tract infection. URTI = upper respiratory } \\
\text { tract infection. }\end{array}$} \\
\hline
\end{tabular}

The allocation to the pop-up intervention was not random, but was determined by the type of EPR system used by the GPs. However, there were no significant differences in prescribing or dispensing rates between the groups at baseline. The pop-up control GPs had larger patient lists and more of them worked in rural and solo practices compared with the pop-up intervention GPs. However, all of these variables were included in the logistic regression analyses, adjusting for any effects these differences may have made.

There was no record of the use of delayed prescribing among the GPs who did not have the pop-up software installed. It is probable that these participants also used the strategy to some extent, as some GPs 
Table 5. Delayed prescribing rate, crude and adjusted odds ratios for issuing a delayed prescription. Multilevel logistic regression analysis of pop-up answers $(n=10860)$, intervention period

\begin{tabular}{|c|c|c|c|c|c|}
\hline & $\begin{array}{l}\text { Delayed } \mathbf{R x} \\
\text { elayed prescribing rate in \%) }\end{array}$ & Crude OR $(95 \% \mathrm{CI})$ & $P$-value & Adjusted OR (95\% CI) & $P$-value \\
\hline Total & $1194(11.0)$ & & & & \\
\hline \multicolumn{6}{|l|}{ GP factors ${ }^{a}$} \\
\hline \multicolumn{6}{|l|}{ Sex } \\
\hline Male & $636(8.8)$ & 1 (Reference) & & 1 (Reference) & \\
\hline Female & 558 (15.5) & 1.63 (1.05 to 2.53 ) & 0.030 & 1.32 (0.78 to 2.25 ) & 0.300 \\
\hline Urban practice & 709 (11.3) & 1 (Reference) & & 1 (Reference) & \\
\hline Rural practice & $485(10.6)$ & $0.81(0.52$ to 1.26$)$ & 0.360 & $0.92(0.58$ to 1.46$)$ & 0.720 \\
\hline \multicolumn{6}{|l|}{ Practice type } \\
\hline Group practice & $1116(11.5)$ & 1 (Reference) & & 1 (Reference) & \\
\hline Solo practice & $78(7.0)$ & 0.65 (0.32 to 1.32$)$ & 0.230 & $0.58(0.27$ to 1.27$)$ & 0.180 \\
\hline \multicolumn{6}{|l|}{ GP specialist } \\
\hline GP specialist & $973(10.4)$ & 1 (Reference) & & 1 (Reference) & \\
\hline \multicolumn{6}{|l|}{ Patient factors } \\
\hline \multicolumn{6}{|l|}{ Type of ARTI } \\
\hline URTI and RT symptoms & 369 (16.3) & 1 (Reference) & & 1 (Reference) & \\
\hline Acute tonsillitis & $77(5.6)$ & $0.27(0.21$ to 0.36$)$ & $<0.001$ & 0.24 (0.19 to 0.32 ) & $<0.001$ \\
\hline Acute sinusitis & 277 (13.3) & $0.73(0.61$ to 0.88$)$ & 0.001 & $0.79(0.65$ to 0.95$)$ & 0.010 \\
\hline Acute bronchitis & $122(7.2)$ & $0.44(0.35$ to 0.55$)$ & $<0.001$ & $0.52(0.41$ to 0.65$)$ & $<0.001$ \\
\hline Pneumonia & $49(2.9)$ & 0.12 (0.08 to 0.16$)$ & $<0.001$ & 0.15 (0.10 to 0.20$)$ & $<0.001$ \\
\hline Acute otitis media + ear pain & $243(19.2)$ & $1.16(0.96$ to 1.42$)$ & 0.130 & $0.97(0.78$ to 1.20$)$ & 0.760 \\
\hline Other RTIs & 57 (11.8) & $0.63(0.45$ to 0.88$)$ & 0.007 & 0.64 (0.45 to 0.89$)$ & 0.009 \\
\hline \multicolumn{6}{|l|}{ Sex } \\
\hline Male & $428(9.7)$ & 1 (Reference) & & 1 (Reference) & \\
\hline Female & 766 (11.9) & $1.17(1.02-1.33)$ & 0.023 & 1.26 (1.10 to 1.45$)$ & 0.001 \\
\hline \multicolumn{6}{|l|}{ Age } \\
\hline$\leq 6$ & 243 (15.9) & 1 (Reference) & & 1 (Reference) & \\
\hline $19-44$ & 493 (12.3) & 0.72 (0.60 to 0.86$)$ & $<0.001$ & 0.80 (0.65 to 0.99 ) & 0.040 \\
\hline $45-64$ & 201 (8.0) & $0.47(0.38$ to 0.59$)$ & $<0.001$ & $0.55(0.43$ to 0.70$)$ & $<0.001$ \\
\hline $65-79$ & $54(5.1)$ & $0.26(0.19$ to 0.36$)$ & $<0.001$ & $0.37(0.26$ to 0.52$)$ & $<0.001$ \\
\hline$\geq 80$ & $17(4.6)$ & $0.24(0.14$ to 0.41$)$ & $<0.001$ & 0.39 (0.23 to 0.68$)$ & 0.001 \\
\hline
\end{tabular}

${ }^{a}$ Adjusted for clustering by random intercepts at GP and CME group level. ${ }^{b}$ The GP factors age, patient encounters/year, listed patients and antibiotics prescribing rate were non significant, and are omitted from the table. $A R T I=$ acute respiratory tract infection. OR = odds ratio. $R T=$ respiratory tract. $R T I=$ respiratory tract infection. URTI = upper respiratory tract infection.

report having used the strategy for years without being taught to do so. ${ }^{15}$ In addition, there was no record of the patients' actual antibiotic consumption. Patients may have dispensed the prescription without consuming the medication, or they may have acquired antibiotics from other sources and left the prescription undispensed.

\section{Comparison with existing literature}

Dispensing rate: baseline. In the research literature, failure to fill medication prescriptions is seen as an unwanted phenomenon and referred to as primary medication non-adherence. The prevalence of primary medication non-adherence varies between study settings from $2.5 \%{ }^{23}$ to $35 \% .{ }^{24}$ Reports on patient adherence to antibiotics compared with other drug classes have produced conflicting results. In the US, Fischer et a ${ }^{25}$ found that $72 \%$ of 82245 electronically transmitted prescriptions (e-prescriptions) for new medications were filled, while the fill rate for prescriptions for antimicrobial drugs was $80 \%$. In Sweden, Ax et al ${ }^{23}$ found that as much as $97.5 \%$ of e-prescriptions were filled, while $96.5 \%$ of antibiotics were dispensed.

Consumption rates of antibiotics are considerably lower than dispensing rates. A meta-analysis found an overall antibiotics adherence rate of $62.2 \%,{ }^{26}$ and a recent 
study on adherence to prescribed antibiotics for acute cough found adherence to at least a 3 -day course in only $57.8 \%$ of patients. ${ }^{27}$ The adherence rate varied across the different European networks participating in the study, with the highest rates being in Scandinavian countries (Norway: $85.7 \%$ ). This study's baseline antibiotic-dispensing rate of $92.1 \%$ is consistent with this pattern.

Dispensing rate: delayed prescribing. The dispensing rate for delayed prescriptions in this study was $59.2 \%$. This is higher than any consumption rate reported in randomised controlled trials (RCTs) or surveys on delayed prescribing for RTIs $\left(24 \%{ }^{6}-53 \%{ }^{28}\right)$. There are several possible explanations for this high rate. The GPs in the current study may have been less emphatic in delivering the wait-and-see advice to patients compared with GPs in RCTs on delayed prescribing. Furthermore, the patients in this study were given the delayed prescription at the time of their consultation, whereas in many of the delayed-prescribing RCTs, patients had to return to their GP's surgery to pick up the prescription. 6,29,30 The latter strategy seems to result in lower consumption rates.

In addition, patients in the current study may have dispensed the prescription for antibiotics but then not taken the medication. Two questionnaire studies on delayed prescribing indicate that $15 \%^{28}$ and $11 \%^{31}$ (personal communication, not reported in the paper) of patients stated that they did not consume the antibiotics, even though they had filled the prescription. Applied to the current study, this corresponds to a $50-53 \%$ consumption rate. This indicates that patients receiving a delayed prescription as part of routine care do, in fact, adopt a wait-and-see approach, but probably to a lesser extent than patients in a controlled trial setting.

Competing interests

Svein Gjelstad has ownership in the company that produces the pop-up reminder and data-extraction software used in the trial and works there part time. The other authors declare no competing interests.

\section{Acknowledgements}

We thank all participating GPs, the outreach visit GPs, Ingvild Dalen for statistical support, and the Rx-PAD study planning group.

\section{Discuss this article}

Contribute and read comments about this article on the Discussion Forum: http://www.rcgp.org.uk/bjgp-discuss prescribing. The absolute reduction in dispensing rate between the pop-up intervention and the educational intervention was $1.6 \%$. A Cochrane review of on-screen, point-of-care computer reminders concludes that such interventions generally result in small-to-modest improvements in provider behaviour. ${ }^{33}$ In multifaceted interventions that aim to improve process adherence, the median effect of the computerised reminder alone was 1.9\%.

In the pop-up intervention group, 11\% of the patients who were prescribed antibiotics for an RTI received a delayed prescription. For acute bronchitis, the rate was $7.2 \%$. An observational study on delayed prescribing for acute cough in 14 primary care networks in 13 European countries ${ }^{13}$ found that $11.8 \%$ of the patients that received a prescription received a delayed prescription; the rate for the participating Norwegian network was 6.6\%, while the highest rate of $53 \%$ was found in the network in the UK. Acute cough and acute bronchitis are not interchangeable categories, and participants in the observational study were not encouraged to use delayed prescribing. Nevertheless, a comparison with this study may indicate that the use of delayed prescribing is relatively infrequent in Norway. This may be related to the low rate of prescriptions for antibiotics in Norway; in the Norwegian network, antibiotics were prescribed in 30\% of the consultations, whereas the rate for all networks was $52.4 \%$. A qualitative study among a selection of the participating GPs revealed that they had strict requirements with regard to when, and whom, they offered delayed prescriptions. ${ }^{15}$ This may also explain the infrequent use of delayed prescribing found in this study.

This study's findings contradict concerns that advocating delayed prescribing as a tool to lower unnecessary antibiotic use would lead to a lower threshold for issuing antibiotic prescriptions. ${ }^{15}$ In this study, the pop-up intervention GPs did not prescribe antibiotics more frequently than the controls.

\section{Implications for practice}

Promoting delayed prescribing through lectures and group visits alone is insufficient to influence medication-dispensing rates. However, adding a constant reminder of the delayed-prescribing option through a computerised pop-up message decreases the number of filled prescriptions. The decrease is small, reflecting that the interventions resulted in a low use of the strategy. 
Delayed prescribing as a strategy for decreasing antibiotic consumption is most effective in children and in adults with otitis, sinusitis, or upper RTIs. Given the small absolute effect of the pop-up reminder, this software can hardly be recommended for general use alone. However, pop-up reminders deserve further evaluation as part of a multifaceted approach in clinical practice. The reported interventions to promote delayed prescribing were embedded in a larger study aiming to decrease antibiotic prescription rates. When promoting delayed prescribing, this should be accompanied by the basic message of not prescribing antibiotics at all when they are not considered necessary.

The dispensing rate is a valuable measurement in antibiotic stewardship research. As is the case with rates of prescriptions for antibiotics, both medication-dispensing rates and delayedprescribing rates vary widely between countries. The potential for delayed prescribing seems to be low in Norway, possibly because of a relatively low rate of prescriptions for antibiotics. Having a measure of the potential of delayed prescribing that is specific to a particular setting is an important consideration when planning interventions that promote prudent antibiotic use within that setting. 


\section{REFERENCES}

1. Straand J, Rokstad KS, Sandvik H. Prescribing systemic antibiotics in general practice. A report from the More \& Romsdal Prescription Study. Scand J Prim Health Care 1998; 16(2): 121-127.

2. Gjelstad S, Dalen I, Lindbaek M. GPs' antibiotic prescription patterns for respiratory tract infections - still room for improvement. Scand J Prim Health Care 2009; 27(4): 208-215.

3. Arroll B. Antibiotics for upper respiratory tract infections: an overview of Cochrane reviews. Respir Med 2005; 99(3): 255-261.

4. Arnold SR, Straus SE. Interventions to improve antibiotic prescribing practices in ambulatory care. Cochrane Database Syst Rev 2005; (4): CD003539.

5. Ranji SR, Steinman MA, Shojania KG, et al. Interventions to reduce unnecessary antibiotic prescribing: a systematic review and quantitative analysis. Med Care 2008; 46(8): 847-862

6. Little P. Gould C. Williamson I, et al. Pragmatic randomised controlled tria of two prescribing strategies for childhood acute otitis media. BMJ 2001; 322(7282): 336-342.

7. Little P. Williamson I, Warner G, et al. Open randomised trial of prescribing strategies in managing sore throat. BMJ 1997; 314(7082): 722-727.

8. Arroll B, Kenealy T, Goodyear-Smith F, et al. Delayed prescriptions. BMJ 2003; 327(7428): 1361-1362

9. Lindbæk M. Prescribing antibiotics to patients with acute cough and otitis media. Br J Gen Pract 2006; 56(524): 164-166.

10. Little P. Delayed prescribing - a sensible approach to the management of acute otitis media. JAMA 2006; 296(10): 1290-1291.

11. National Institute for Health and Clinical Excellence. Prescribing of antibiotics for self limiting respiratory tract infections in adults and children in primary care. National Institute for Health and Clinical Excellence, 2008

12. The Directorate of Health. The antibiotic center for primary health care. [National guidelines for antibiotic use in primary health care]. Oslo: The Directorate of Health, 2008.

13. Francis NA, Gillespie D, Nuttall J, et al. Delayed antibiotic prescribing and associated antibiotic consumption in adults with acute cough. Br J Gen Pract 2012; 62(602): 639-646.

14. Spurling GK, Del Mar CB, Dooley L, et al. Delayed antibiotics for respiratory infections. Cochrane Database Syst Rev 2007; (3): CD004417.

15. Høye S, Frich J, Lindbæk M. Delayed prescribing for upper respiratory tract infections: a qualitative study of GPs' views and experiences. Br J Gen Pract 2010; 60(581): 907-912

16. Peters S, Rowbotham S, Chisholm A, et al. Managing self-limiting respiratory tract infections: a qualitative study of the usefulness of the delayed prescribing strategy. Br J Gen Pract 2011; 61(590): e579-e589.

17. Butler CC, Simpson SA, Dunstan F, et al. Effectiveness of multifaceted educational programme to reduce antibiotic dispensing in primary care: practice based randomised controlled trial. BMJ 2012; 344: d8173.

18. Sharland $M$, Kendall $H$, Yeates $D$, et al. Antibiotic prescribing in general practice and hospital admissions for peritonsillar abscess, mastoiditis, and rheumatic fever in children: time trend analysis. BMJ 2005; 331(7512): 328-329.

19. Gjelstad S, Fetveit A, Straand J, et al. Can antibiotic prescriptions in respiratory tract infections be improved? A cluster-randomized educational intervention in general practice - the Prescription Peer Academic Detailing (Rx-PAD) Study [NCT00272155]. BMC Health Serv Res 2006; 6: 75.

20. Antibiotics in general practice. Oslo: Norwegian Board of Health Supervision; 2000

21. Zhang J, Yu KF. What's the relative risk? A method of correcting the odds ratio in cohort studies of common outcomes. JAMA 1998; 280(19): 1690-1691.

22. Gjelstad S, Straand J, Dalen I, et al. Do general practitioners' consultation rates influence their prescribing patterns of antibiotics for acute respiratory tract infections? J Antimicrob Chemother 2011; 66(10): 2425-2433.

23. Ax F, Ekedahl A. Electronically transmitted prescriptions not picked up at pharmacies in Sweden. Res Social Adm Pharm 2010; 6(1): 70-77.

24. Kajioka EH, Itoman EM, Li ML, et al. Pediatric prescription pick-up rates after ED visits. Am J Emerg Med 2005; 23(4): 454-458.

25. Fischer MA, Stedman MR, Lii J, et al. Primary medication non-adherence: analysis of 195,930 electronic prescriptions. J Gen Intern Med 2010; 25(4): 284-290.

26. Kardas P, Devine S, Golembesky A, et al. A systematic review and meta-analysis of misuse of antibiotic therapies in the community. Int J Antimicrob Agents 2005; 26(2): 106-113.

27. Francis NA, Gillespie D, Nuttall J, et al. Antibiotics for acute cough: an international observational study of patient adherence in primary care. $\mathrm{Br} J \mathrm{Gen}$ Pract 2012; 62(599): e429-e437.

28. Edwards M, Dennison J, Sedgwick P. Patients' responses to delayed antibiotic prescription for acute upper respiratory tract infections. Br J Gen Pract 2003; 53(496): 845-850

29. Dowell J, Pitkethly M, Bain J, Martin S. A randomised controlled trial of delayed antibiotic prescribing as a strategy for managing uncomplicated respiratory tract infection in primary care. Br J Gen Pract 2001; 51(464): 200-205.

30. Little $\mathrm{P}$, Gould $\mathrm{C}$, Williamson I, et al. Reattendance and complications in a randomised trial of prescribing strategies for sore throat: the medicalising effect of prescribing antibiotics. BMJ 1997; 315(7104): 350-352.

31. Høye S, Frich JC, Lindbaek M. Use and feasibility of delayed prescribing for respiratory tract infections: a questionnaire survey. BMC Fam Pract 2011; 12: 34.

32. Davis DA, Thomson MA, Oxman AD, et al. Evidence for the effectiveness of CME. A review of 50 randomized controlled trials. JAMA 1992; 268(9): 1111-1117.

33. Shojania KG, Jennings A, Mayhew A, et al. The effects of on-screen, point of care computer reminders on processes and outcomes of care. Cochrane Database Syst Rev 2009; (3): CD001096. 